\title{
A Research on the System of Dragon Boat Course in Chinese Universities
}

\author{
Yaohui Lin \\ Tan Kah Kee College \\ Xiamen University \\ Xiamen, China
}

\begin{abstract}
Dragon boat sport is an ancient activity originated from China with over two thousand years history. Now with the society and economy developing, dragon boat sport and modern culture have merged together while a growing number of people recognized it. On the other hand, many universities put their emphasis on the physical education, particularly on sport, and some of these universities have been starting to offer dragon boat course which is popular among students. These signs indicate that dragon boat sport, a traditional activity, now is shifting its position to the line of modern education. However, it is undeniable to admit dragon boat sport existed in history for a very long time but relatively a short time in school education. Somehow it caused the problem of discordant development between dragon boat sport and schooling. And the problem mainly reflects on the study of theory tends to lag behind practice. Moreover, it is hardly to cite books or papers with comparative authority and influence. Therefore, it is believed that there must be some problems in the process of constructing systems of dragon boat course. And it directly affects the developing of dragon boat sport in universities. Through the investigation on the system of dragon boat sport, we hope to find solutions and then propose reasonably in order to provide these universities with theoretical basis and practical guidance. And finally, dragon boat sport can urge a better development.
\end{abstract}

Keywords—universities; dragon boat; course; construction

\section{THE DEFINITION OF DRAGON BOAT SPORT}

The dragon boat sport is an activity based on the individual blade with oarsmen by using muscle power as thrust force pulling the boat forward. This campaign, usually held outside, belongs to physical performance leading category and events of antagonism. The setting of dragon boat can be divided into four parts which are drummers, helmsmen, tail and head. This kind of setting can utmostly guarantee the traditional purity of dragon boat sport.

Whereas the concept of dragon boat course is still unclear in China now. Encyclopadia Sinica gives us definition in terms of general and narrow side. On the side of general definition, course is the sum of all subjects or activities which are under the guidance of teachers. On the side of narrow definition, course refers to one specific subject. With understanding of all the definitions above, this paper is specified in the following aspects: current situation of dragon boat course in universities, the construction of course system in universities, teaching content, teaching goal, evaluation index, extracurricular activities and school environment.

\section{THE CURRENT SituAtion OF DRAGON BoAT COURSE IN UNIVERSITIES}

"21st Higher Education Teaching Content and Curriculum System Reform Plan" promulgated in 1994 by the national Ministry of Education, since its establishment, the plan has long been played a significant role in national education and it achieves remarkable success in terms of education work. Nevertheless, due to its extensive content, this plan is unable to reach every detailed field. Shortcomings still remain.

Rowing and Dragon Boat Branch of Federation of University Sports of China was established in 2004 in Tianjin University of Technology. The branch is aim to promote the development of dragon boat sport and enhance influence of dragon boat sport, and furthermore, to build up college students' bodies. In addition, the national Ministry of Education approved a plan in 2005 which announced ten universities as experimental unit. Henceforth, the dragon boat sport entered an unprecedented era of development. And many universities are gradually paying attention to the developing of dragon boat sport. Thus this sport has got a certain achievement in universities.

At present, with the campaign level constantly upgrade and certain progress have been made, but we still cannot ignore the fact of the study of theory tends to lag faraway behind practice. For example, the dragon boat course is conducted commonly in the form of elective course. And contents of the course are normally the origins of dragon boat, the history or the current development, as for its technical part is rare.

The method of how to teach and the important or difficult points in the process of teaching occupy a little part in the system of dragon boat course. Therefore the perfection of the course is the first priority to make contribution to the dragon boat development in university. 


\section{THE CONSTRUCTION OF COURSE SYSTEM IN UNIVERSITIES}

The construction of course system is a rigorous work which covers a wide field. It is the core and initial work of giving an excellent lesson. From domestic and abroad literature we can see the main part of course system including: value, content, training and teaching objectives, settings, evaluation and strategy.

\section{A. The Major Content of Course System Construction}

The course system is the initial part in teaching, which compares to the foundation of a house. The quality of the foundation directly decides the height of a house and how long you are able to live in as well. Therefore, the construction of the course system is the prior and most important work. Objectives, physical fitness, teaching materials, contents and methods, teaching level and evaluation must be considered as integrated factors when drawing up the construction plan.

In terms of the students of dragon boat course, firstly, we should have a clear and definite awareness on who the target people really are. It is believed that there are fundamentally two groups of people who are involved in dragon boat sport. One part is students who major in dragon boat sport. They are usually students with special sports skills, and they are aim to enhance the sport proficiency in order to participate in competition and win honor for school and themselves. Another part is students who love this sport. On the one hand, they row the boat for their interests and hobbies. On the other hand, they can build their body as well. Based on these two factors, dragon boat course has to meet the need of students, and be suitable to the teaching circumstances, and promote and improve the level of students.

\section{B. The Training Objective of Dragon Boat Course}

Educationally, training objective compares to the lighthouse, which indicates directions. There are short-term, mid-term and long-term objectives in training. Short-term objective aims at one single unit or one lesson. And midterm objective aims at one semester or a longer period. Furthermore, a long-term objective refers to the expectation of what student can eventually master in the period of final learning. These three objectives are relatively connected in the process of teaching. Colloquially, status of short-term objective can affect the achievement of mid-term objective, and necessarily affect the long-term objective. Thus we are asked to pay attention to every phase of objective.

The educational objective of dragon boat course is to meet the need of taking exercise, which enjoys perceptiveness and comprehensiveness. However, it is not only aim to train students' bodies. What's more important is to imbue a passion of traditional culture and a feeling of patriotic.

The construction of dragon boat course is an important step on the rough road to the summit of university education. According to the guiding concept of "Keeping Healthy First, Taking Exercise Forever.", rely on the dragon boat sport, we can combine tradition and contemporary to urge a better development. Firstly, increase influence of dragon boat sport in schools. Secondly, depend on the school and media. Finally, enhance the influence of dragon boat sport in society.

From the perspective of school, we will see students' bodies getting stronger and a increasing in cohesion and united force and fighting spirit as well. Meanwhile, through the retrospect of the history of dragon boat sport, we believe students' patriotic enthusiasm step up continuously.

1) The Teaching Objective of Dragon Boat Course club: Teaching is always the prime work in school, and it is the core of education as well. While in teaching, the content must be based on the teaching objective. Withe optimization of each link of education, we shall constantly approach the objective of teaching and finally improve the process of it. In the same way, school teachers, who are responsible for dragon boat course, should have been thinking whether the result can fulfil the expected goal, as far as they are giving lessons.

At present, the specific teaching objective of dragon boat sport is various. In terms of spirit, we wish students a love for their country and a brave for themselves. In terms of skills, we hope they can master how to row. In terms of physical fitness, we except their strong bodies and good spiritual outlooks.

\section{Settings of Dragon Boat Course}

The outline and the system of classroom learning, extracurricular learning and self-learning form the course. And the course is the specific component of teaching objective.

Due to the particularity of dragon boat sport, teaching arrangement is limited by the weather and yard. Therefore, schools in different regions should take into consideration that teaching arrangement must be suitable for the local climatic feature. For example, in northern China, the lake has the strong possibility of getting frozen after autumn. And schools have to discontinue the course and all the training. However, from my perspective, teachers can carry out practice learning first and then teach theoretical lessons when the weather gets colder. Reasonable arrangements can ensure the whole teaching process goes smoothly.

\section{Contents of Dragon Boat Course}

The course content is one of the most important parts of the system of dragon boat course. And it is also the significant factor in teaching. The degree of difficulty has to match the learning condition of students. After a discussion with experts in dragon boat sport and a study on the textbook of dragon boat sport, this paper will divide contents of dragon boat course into three parts followed: Basic Theory, Practice and Judicial Rules.

In terms of basic theory, it mainly includes concept, origin, history, scope, etiquette, skills, theories and so on. Sailing and rowing skills with drummer and helmsman's action tips belong to practice part. And by knowing judicial 
rules, students can master how to compete correctly in the dragon boat sport. Avoiding any nonstandard actions can ensure the competition goes smoothly.

Teachers usually adopt integrated teaching method or decomposing teaching method in teaching. Adopting which method depends on the content. To those relatively simple training, teachers firstly decompose and then integrate the training action. On the contrary, to those relatively complex training, teachers integrate firstly. Normally speaking, with the rise of students or athletes' training level, the proportion of decomposing teaching should be increased constantly. The more high-level-atheles there are, the more decomposing teaching methods should be adopted. Because decomposing teaching can correct and avoid wrong actions.

Dragon boat sport requires a strong body. And some of students cannot act in right place. The reason is the lack of physical coordination and quality. Besides theoretical teaching, students also need training on their own bodies, on account of physical quality determines the sport development of student.

While in teaching, according to arrangements and settings of content, teachers are teaching in a step by step process. Students have to learn the basic theory before they get on board. By mastering the supporting skill, we can finally reach the training objective.

\section{E. Evaluation of Dragon Boat Course}

Evaluation of dragon boat course refers to an appraisal of the value of study, and it is a final step of the teaching process and a test on students' study achievements. In addition, evaluation, after a period of learning, makes students rethink their authentic study results. It is believed evaluation can enhance students' effect and ability of learning, and what's more, promote the growth of students. Also through the evaluation, we can tell the effects of the system of course because if the students learn well, the evaluation will show a good result. Otherwise, the system of dragon boat course should be improved.

At present, there are mainly three dimensions for the evaluation of dragon boat course. First is classroom performance of students, and it is embodied in the attitude, enthusiasm and cooperation with teachers or classmates. And second is the level of theory of students reflected by the examination. There are a great number of teachers who would be likely to give students more of a sense of written examination. And third is the examination of the practice skills. By giving drummers, helmsmen and rowers an objective evaluation, teachers will have awareness in general.

The evolution of dragon boat sport is a combination of comprehensive factors. Universities can supervise and improve the development of dragon boat sport by establishing Dragon Boat Association. This could change people's view on dragon boat sport and advance the development of dragon boat sport.

\section{PRoblems to Be SOlVEd IN THE PROCESS OF CONSTRUCTING COURSE SYSTEM}

\section{A. Lack of Equipment}

Equipment is the base of dragon boat training. The distinctiveness of dragon boat sport determines some of universities are unable to provide qualified field to support the training. However, by simulating the real training condition, students can still learn the basic skill of rowing. Furthermore, gym in university can also help these students build their bodies in order to strengthen their physical power. Through the way of combining practical and theoretical learning together, teachers may solve the problem of lack of equipment.

\section{B. Lack of Teachers}

Not many universities have teachers who specialize in dragon boat sport. However, universities can regularly hire experts to give P.E. teachers training lessons, in order to raise their professional level. If condition allowed, school dragon boat team may participate in the competition. It is believed that could be the best way to improve both teachers and students' abilities.

\section{Lack of Finical Support}

The finical support is the decisive factor of a project. Therefore, the degree of emphasis of the head determines the efficiency of finical support. Whether the dragon boat sport develops smoothly or inconveniently, the result mainly depends on the finical support.

\section{CONCLUSION}

Currently, the system of dragon boat course is not quite perfect, and it needs improvement immediately. And the contents of course system are followed: value, content, training and teaching objectives, settings, evaluation and strategy. The training objectives of dragon boat course are three dimensions: spirit, skill and physical fitness. The features of dragon boat course are basic theory, practice and judicial rules.

We believed $\mathrm{t}$ an impeccable course system should contain evaluation and detection. At the same time, we establish Dragon Boat Association to supervise the process of development. Above all, we shall take every possible chance to improve and develop this sport continuously.

\section{REFERENCES}

[1] Huang Hansheng, Mei Xuexiong, Chen Junqin. Research on the Reform of Education Professional Curriculum System in Chinese Universities [J], Sports Science, 1998, 18(6): 1-4

[2] Zhang Jianshi. Dragon Boat and Races in China [M], Beijing: Huaxia Publishing House, 1988

[3] Ma Yong, He Zhaoze. The Development and Characteristics of Dragon Boat Race [J], Journal of Jilin Institute of Physical Education, 2006, 1

[4] Ni Yike. The Thinking on the Development of Traditional Chinese Sports: the Modernization of Chinese Dragon Boat Sport [J], Sports Science, 2004, 4 
[5] Yang Luosheng. Research Status and Literature Review of Dragon Boat Race [J], Journal of Lingling University, 2004, 7. 